\title{
FOLR1 increases sensitivity to cisplatin treatment in ovarian cancer cells
}

\author{
Ming-ju Huang ${ }^{1,2+}$, Wei Zhang ${ }^{1 \dagger}$, Qi Wang ${ }^{1}$, Zhi-jun Yang ${ }^{1}$, Sheng-bin Liao ${ }^{1}$ and $\mathrm{Li} \mathrm{Li}^{1^{*}}$
}

\begin{abstract}
Background: Whether there is a mechanistic link between FOLR1 and response to cisplatin has not been extensively examined. In this study, we determine the expression of FOLR1 in ovarian cancer and examine if FOLR1 levels influence response to cisplatin.

Results: (1) FOLR1 protein expression was lowest in normal ovarian tissue, higher in benign ovarian tumors, and highest in malignant tumors $(P<0.01)$. (2) FOLR1 expression was decreased in platinum drug-resistant ovarian tumors compared to sensitive tumors $(P<0.01)$. Consistent with this, FOLR1 expression in tumors progressing following cisplatin treatment was lower than levels in tumors in remission $(P<0.01)$. (3) FOLR1 was successfully overexpressed at both the mRNA and protein levels following transfection in SKOV3 cells. (4) SKOV3 cells with FOLR1 overexpression were the most sensitive to cisplatin treatment $(I C 50=3.60 \mu \mathrm{g} / \mathrm{ml})$ and exhibited the highest inhibition rates in the presence of the drug $(P<0.05)$. (5) The rate of apoptosis of SKOV3 cells increased with cisplatin treatment in a dose- and time-dependent manner $(P<0.05)$. Cisplatin also induced $\mathrm{S}$ phase arrest in a concentration-dependent manner $(P<0.05)$. Apoptosis and $\mathrm{S}$ phase proportion were significantly altered by FOLR1 overexpression $(P<0.05)$.
\end{abstract}

Conclusion: FOLR1 may be a useful biomarker for ovarian cancer, and it may be useful as a therapeutic application to improve sensitivity to cisplatin treatment.

Keywords: Folate binding protein, Ovarian cancer, SKOV3 cells, Cisplatin, Apoptosis, Cell cycle, Multidrug resistance

\section{Background}

Ovarian cancer is a serious malignancy, with high mortality and a five-year survival rate of approximately $20 \%-30 \%$ for the prevailing advanced presentations [1]. Survival in patients with ovarian cancer can be improved with early detection, thorough surgery, and improved sensitivity to cisplatin-based chemotherapy. Folate binding protein (FOLR1) is a member of the human folate binding protein family. The gene is located on chromosome 11q13.3-14.1. FOLR1 is a glycosyl phosphatidylinositol connected membrane glycoprotein, consisting of 257 amino acids. The protein is completely exposed to extracellular molecules and anchored at the cell membrane by GPI [2]. FOLR1 is involved in DNA replication and damage repair. Its expression levels are closely related with tumor progression and cell proliferation [3, 4]. FOLR1, also known as folate

\footnotetext{
* Correspondence: LiLi@gxmu.edu.cn

'Equal contributors

'Department of Gynecology Oncology, Tumor Hospital of Guangxi Medical University, Nanning 530021, China

Full list of author information is available at the end of the article
}

receptor proteins, mediates cellular responses to folate, including cell division, proliferation, and tissue growth [5]. Few publications have reported on FOLR1 expression in ovarian tissue. Shen et al. found that FOLR1 expression was decreased in cisplatin-resistant tumors [6],but whether there is a mechanistic link between FOLR1 and response to cisplatin has not been extensively examined. In this study, we determine the expression of FOLR1 in ovarian cancer and examine if FOLR1 levels influence response to cisplatin. The data we provide here suggest that FOLR1 may be a useful predictive biomarker for cisplatin sensitivity in ovarian cancer.

\section{Results}

Expression of FOLR1 in normal ovary, benign ovarian tumors, and ovarian cancer

Expression of FOLR1 in normal, benign, and cancerous ovarian tissues was determined by Western blot. GAPDH was used as a loading control. Expression of FOLR1 was lowest in normal ovarian tissue. FOLR1 was 
more highly expressed in benign tumors and even higher in malignant disease $(P<0.01)$ (Fig. 1).

\section{Expression of FOLR1 in cancerous ovarian tissue is correlated with clinicopathologic factors}

FIOG (International Federation of Gynaecology and Obstetrics) system 2000 is used to determine the stages of malignant ovarian patients. The expression of FOLR1 in stage I-II is lower than that in stage III-IV and also lower in the well-differentiated than that in the lowdifferentiated $(P<0.05)$. While there is no difference for expression of FOLR1 in the four different pathologic tissue, the significant difference does exist between the mucinous and the serous $(P<0.05)$. The specific results are shown in Fig. 2.

\section{Correlation of expression of FOLR1 with tumor metastasis} and ascites

Expression of FOLR1 in cancerous ovarian tissue with metastasizing to distant lymph node and/or organ is higher than that without metastasis $(P<0.05)$. However,there's no significance about correlation of expression of FORL1 with whether metastasizing to the greater omentum or having asites $(P>0.05)$. The specific results are shown in Fig. 3.

FOLR1 expression in ovarian cancer tissue is correlated with patient treatment efficacy and drug resistance

FOLR1 protein expression was highest in patients with complete remission (complete response, CR). FOLR1 expression decreased with decreased drug sensitivity (partial response, $\mathrm{PR}>$ stable disease, $\mathrm{SD}>$ progressive disease, $\mathrm{PD})$. The difference in expression in $\mathrm{CR}, \mathrm{PR}$, and SD patients compared to PD patients was statistically significant $(P<0.01)$. The difference in expression in $C R$ and $P R$ patients compared to $\mathrm{PD}$ and $\mathrm{SD}$ patients was also significant $(P<0.05)$. However, there was no statistically significant difference in expression in $\mathrm{CR}$ and $\mathrm{PR}$ patients compared to SD patients $(P>0.05)$. Expression of FOLR1 in platinum drug-resistant ovarian cancer was lower than in platinum drug-sensitive tumors $(P<0.01)$, and after further chemotherapy expression of FOLR1 in PD was still lower than that in remission $(p<0.01)$ (Fig. 4).

\section{Correlation of expression of FOLR1 in ovarian cancer tissue with prognosis of patients}

ROC curve that determines the relationship of FOLR-1 expression and nature of ovarian cancer demonstrates that maximum Youden index is 3.115. The specific result is shown in Fig. 5a.

Univariate analysis of Kaplan-Meier survival curve demonstrates that median overall survival time is 29.4 months for the positive group and 32.3 months for the negative group respectively, and the difference is not statistically significant $(P>0.05)$ (Fig. 5b).

COX multivariate analysis denies expression of FOLR1 as an independent prognostic factor.

\section{FOLR1 expression in transfected SKOV3 cells}

RT-PCR and Western blot were performed to confirm overexpression of FOLR1 at both the mRNA and protein levels in SKOV3 cells following transfection. Neither FOLR1 mRNA nor protein was detected in the empty vector transfected group (pWPI-SKOV3) or in control cells (SKOV3) (Fig. 6).

\section{Growth inhibition and apoptosis of SKOV3 cells treated with cisplatin}

MTT assays were performed and $\mathrm{IC}_{50}$ values of each group were determined in the presence of cisplatin. The $\mathrm{IC}_{50}$ values of SKOV3, pWPI-SKOV3, pWPI-FOLR1SKOV3 cells were 5.01, 4.96, and $3.60 \mu \mathrm{g} / \mathrm{ml}$, respectively. The $\mathrm{IC}_{50}$ to cisplatin of the pWPI-FOLR1-SKOV3 group was significantly lower than the two control

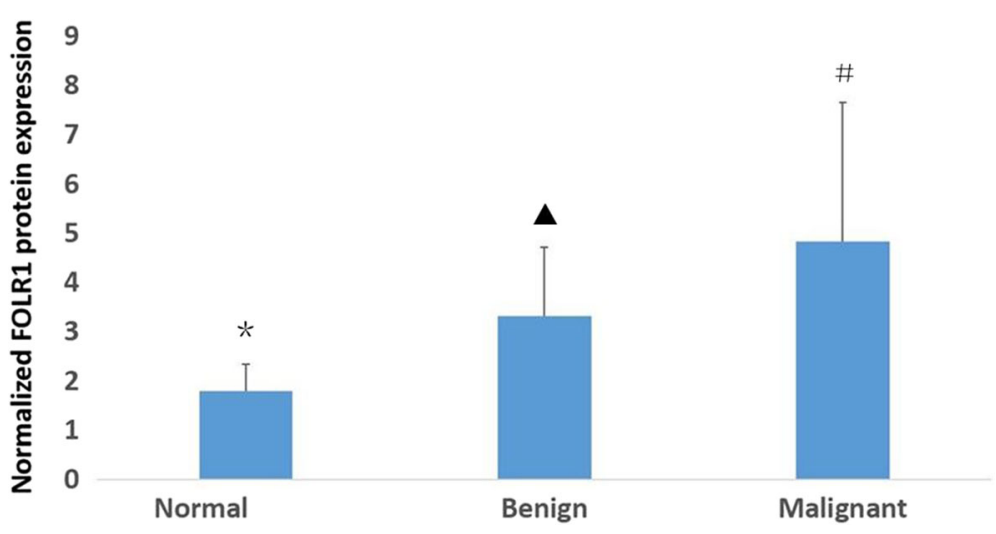

Fig. 1 Ovarian tissues expression of FOLR1 protein detected by western blot.*,P=0.000,compared with benign; $\mathbf{\Delta}, P=0.002$, compared with malignant;,$P=0.000$, compared with normal 


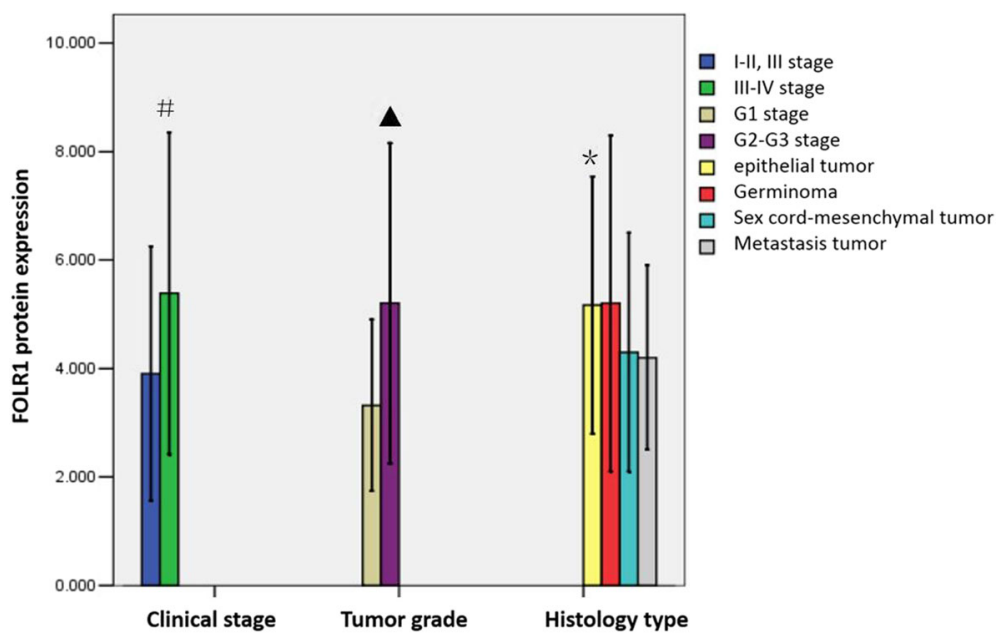

Fig. 2 The comparison for expression of FOLR1 with different clinicopathological factors.\#, $P=0.047$, mucinous vs serous; $\mathbf{\Lambda}, P=0.013, \mathrm{G} 1$ vs G2-G3; ${ }^{*} P=0.013$, stage I-II vs stage III-IV

groups $(P<0.05)$. There was no significant difference in $\mathrm{IC}_{50}$ between the two control groups $(P>0.05)$. For all groups, the growth inhibition rate in the presence of cisplatin increased in both a time- and dosedependent manner. Apoptosis of cells in the three groups increased with cisplatin treatment in a similar manner. Under the same conditions, pWPI-FOLR1SKOV3 cells displayed the highest growth inhibition rate compared to the other two groups $(P<0.05)$. Apoptosis also increased in each of the three groups in a dose- and time-dependent manner. Under the same conditions, pWPI-FOLR1-SKOV3 cells displayed the highest rates of apoptosis compared to the other groups $(P<0.05)$. There was no significant different between the two control groups $(P>0.05)$. The specific results are shown in Table 1.

\section{Cell cycle analysis of cells treated with cisplatin}

Flow cytometry showed that the proportion of pWPIFOLR1-SKOV3 cells in $\mathrm{S}$ phase (no cisplatin treatment) was significantly higher than the proportion in the other two control groups $(P<0.05)$. For all three groups, treatment with cisplatin $(1.8,3.6$, and $7.2 \mu \mathrm{g} /$ $\mathrm{ml})$, increased the percentage of cells in $S$ phase in a dose-dependent manner $(P<0.05)$. Under the same conditions, the percentage of cells in $S$ phase in the pWPI-FOLR1-SKOV3 group was highest compared to the other two groups $(P<0.05)$ (Fig. 7).

\section{Concentration of residual cisplatin in cells detected by} high performance liquid chromatography (HPLC)

The IC50 value in the pWPI-FOLR1-SKOV3 group was used as the reference concentration of cisplatin, and the

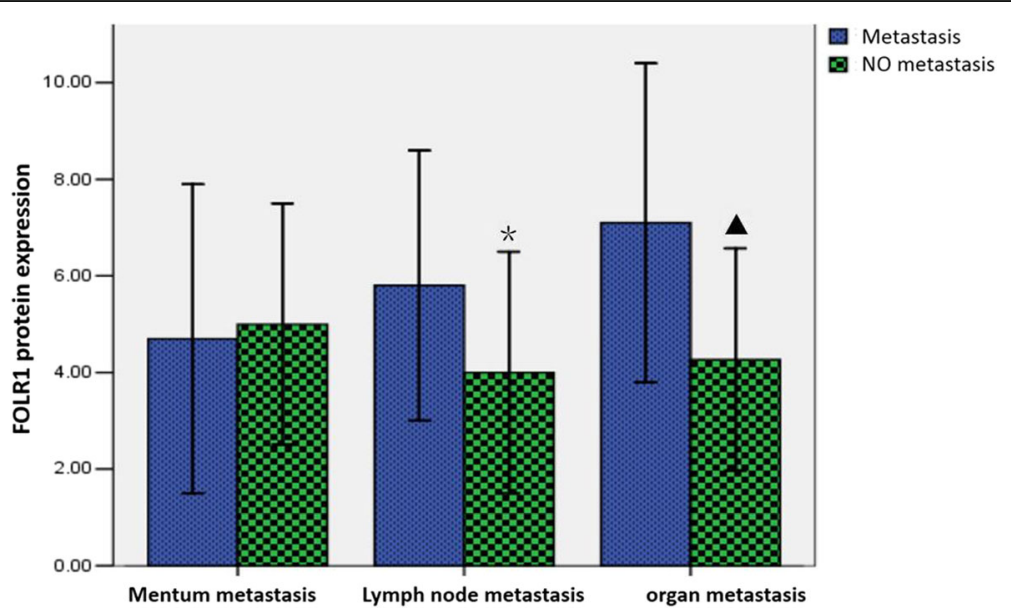

Fig. 3 Comparison of expression of FOLR1 before and after metastasis. ${ }^{*}, P=0.01$, compared with metastasis to lymph node; $\mathbf{\Lambda}, P=0.000$, compared with metastasis to distant organ 

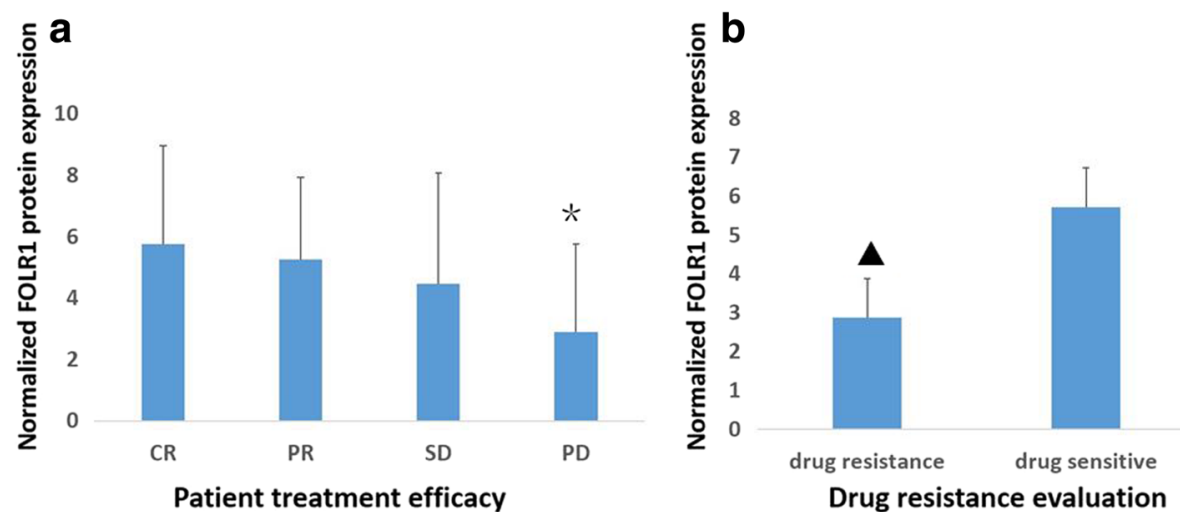

Fig. 4 FOLR1 expression correlated with patient treatment efficacy (a) and drug resistance $(\mathbf{b})$. ${ }^{*}, P=0.001$, compared with $C R+P R+S D ; \boldsymbol{\Lambda}, P=0.000$, compared with drug sensitive. CR, complete response. PR, partial response.SD, stable disease. PD, progressive disease

same concentration of cisplatin was added to the three groups of cells, respectively. After $48 \mathrm{~h}$ of maturing they were used to detect the concentration of residual cispaltin in cells by HPLC (data not shown). Compared with standard curve, residual cisplatin concentration of the three groups were $1.543 \pm 0.109 \mu \mathrm{g} / 10^{6}$ cells, $1.487 \pm 0.115 \mu \mathrm{g} /$ $10^{6}$ cells and $2.604 \pm 0.205 \mu \mathrm{g} / 10^{6}$ cells,respectively. The pWPI-FOLR1-SKOV3 cells displayed the highest concentration compared to the other two groups $(P<0.05)$. There was no significant difference between the two control groups $(P>0.05)$. The specific results are shown in Fig. 8 .

\section{Discussion}

In our previous study, we determined that FOLR1 was highly expressed in 160 ovarian tissue samples. This finding was consistent with another publications [7-9]. We find that FOLR1 is particularly high in cases of ovarian cancer, which suggests that FOLR1 may be useful as a clinical diagnostic marker for the disease. Yuan et al. [10] showed that expression of FOLR1 in ovarian cancer was significantly higher than in either breast cancer or malignant mesothelioma. CA125 has been routinely used as a serum biomarker of ovarian cancer. However, it has proven to be a poor diagnostic indicator of sensitivity and specificity for early stage disease [11]. Thus, additional biomarkers are needed. Combined detection of CA125 and FOLR1 may be useful for the early diagnosis of ovarian cancer [12]. Such combination could also improve specificity and treatment response prediction [13].

Ovarian tumors are typically treated with cytoreductive surgery and platinum-based chemotherapy. However, long-term efficacy is limited. Yakirevich et al. [14] found that only $75 \%$ to $80 \%$ of epithelial ovarian cancers respond to chemotherapy, while the rest display primary resistance. Eventually, all patients develop chemotherapy
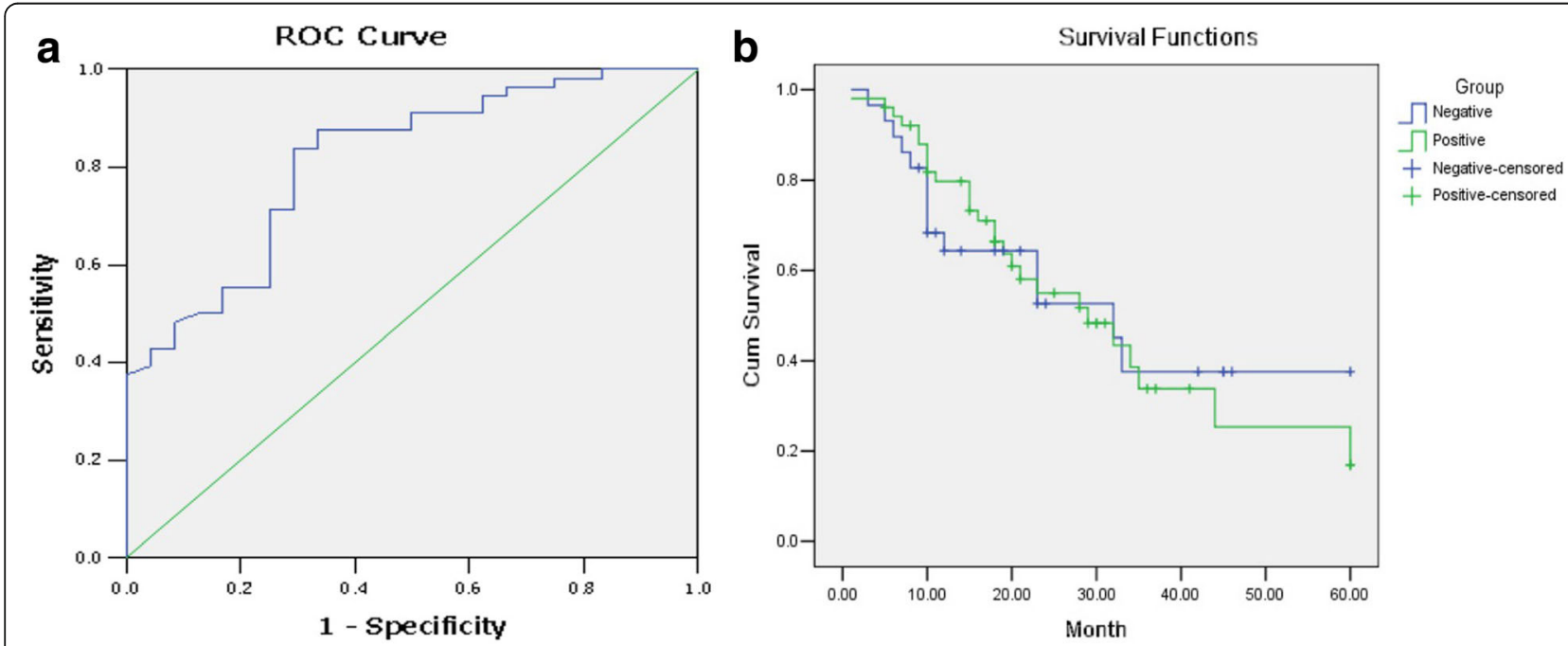

Fig. 5 Expression of FOLR1 associated ROC curve. The maximum Youden index is 3.115 (a).Kaplan-Meier survival curve with cut-off value of expression of FOLR1 (b). The median OS is $29.4 \mathrm{~m}$ for the positive group (expression of FOLR> 3.115), and $32.3 \mathrm{~m}$ for the negative group (expression of FOLR<3.115) 

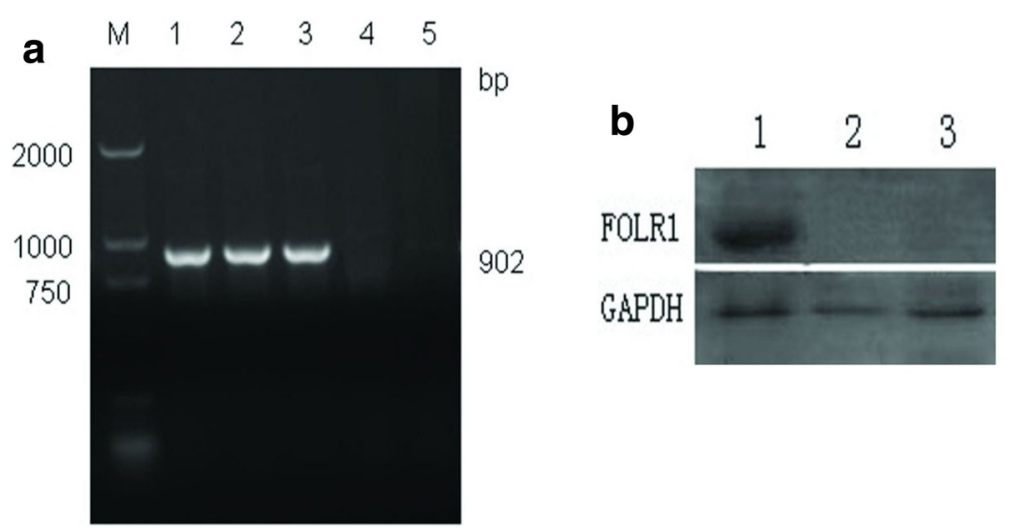

Fig. 6 RT-PCR of FOLR1 in each of the different groups (a) (lane M, DL2000 marker; lanes 1-3, rpWPI-FOLR1-SKOV3 group; lane 4, pWPI-SKOV3 group; lane 5, SKOV3 group). Expression of FOLR1 protein in different groups detected by Western blot (b) (lanes 1, rpWPI-FOLR1-SKOV3 group; lane 2, pWPI-SKOV3 group; lane 3, SKOV3 group)

drug resistance, which contributes to a low five-year survival rate and poor prognosis. We found that expression of FOLR1 is significantly reduced in drug-resistant ovarian tumors compared to drug-sensitive tumors. These findings are consistent with the finding that cisplatinresistant cells display decreased levels of folate binding protein [6]. Decreased expression of FOLR1 in ovarian cancer cells is significantly associated with drug resistance. Thus, this may represent a mechanism of multidrug resistance in the disease. Improvement of drug response has many potential benefits, including improving patient survival. We find that overexpression of FOLR1 in SKOV3 cells changes many of their biological properties, including cell cycle progression and apoptosis. SKOV3 cells overexpressing FOLR1 were the most sensitive to cisplatin treatment $\left(\mathrm{IC}_{50}=3.60 \mu \mathrm{g} / \mathrm{ml}\right)$. These cells also displayed the most growth inhibition following treatment. Our data show that high expression of FOLR1 in ovarian cancer cells increases sensitivity to cisplatin. We hypothesize that FOLR1 may promote ovarian cancer cell growth by transporting folic acid; it may also influence the response to cisplatin. However, more work is needed to determine the mechanism responsible for this effect. In the late 1990s, Gibb et al. [15] found that cisplatin induces apoptosis of ovarian cancer cells. Cisplatin is currently used as first-line chemotherapy for ovarian cancer treatment. Chemoresistance is associated with apoptosis and cell cycle changes. Resistance of ovarian cancer cells to chemotherapy-induced apoptosis is a primary reason for treatment failure $[16,17]$. Cisplatin is induced by the endogenous mitochondrial pathway of apoptosis in ovarian cancer [18]. Here, we show that increased expression of FOLR1 increases sensitivity of ovarian cancer cells to

Table 1 Growth inhibition rate and apoptosis rate of each group of cells treated with different concentrations of cisplatin for different lengths of time

\begin{tabular}{|c|c|c|c|c|c|c|c|}
\hline \multirow[t]{2}{*}{ Group } & \multirow[t]{2}{*}{ Cases } & \multicolumn{3}{|c|}{ Growth inhibition rate } & \multicolumn{3}{|c|}{ Apoptosis rate } \\
\hline & & $24 \mathrm{~h}$ & $48 \mathrm{~h}$ & $72 \mathrm{~h}$ & $24 \mathrm{~h}$ & $48 \mathrm{~h}$ & $72 \mathrm{~h}$ \\
\hline \multicolumn{8}{|c|}{ pWPI-FOLR1-SKOV 3 ( $\mu \mathrm{g} / \mathrm{ml})$} \\
\hline 1.8 & 12 & $8.86 \pm 0.69$ & $17.43 \pm 0.91$ & $30.29 \pm 0.84$ & $16.54 \pm 2.58$ & $24.84 \pm 2.69$ & $32.28 \pm 2.97$ \\
\hline 3.6 & 12 & $18.52 \pm 0.97$ & $50.63 \pm 1.31$ & $64.28 \pm 1.45$ & $19.50 \pm 2.71$ & $50.08 \pm 3.85$ & $65.68 \pm 4.03$ \\
\hline 7.2 & 12 & $32.24 \pm 1.13$ & $67.69 \pm 1.24$ & $79.38 \pm 2.01$ & $35.28 \pm 3.59$ & $71.44 \pm 4.51$ & $79.17 \pm 4.58$ \\
\hline \multicolumn{8}{|c|}{ pWPI-SKOV3 ( $\mu \mathrm{g} / \mathrm{ml})$} \\
\hline 1.8 & 12 & $6.54 \pm 0.45$ & $9.73 \pm 0.67$ & $15.79 \pm 0.32$ & $10.08 \pm 2.19$ & $14.89 \pm 2.58$ & $15.32 \pm 2.61$ \\
\hline 3.6 & 12 & $12.89 \pm 0.73$ & $27.24 \pm 0.85$ & $38.21 \pm 0.89$ & $12.39 \pm 2.06$ & $27.61 \pm 2.77$ & $39.83 \pm 3.19$ \\
\hline 7.2 & 12 & $19.26 \pm 0.89$ & $56.21 \pm 1.04$ & $69.77 \pm 1.43$ & $24.19 \pm 2.78$ & $58.80 \pm 4.11$ & $65.63 \pm 3.91$ \\
\hline \multicolumn{8}{|c|}{ SKOV3 $(\mu \mathrm{g} / \mathrm{ml})$} \\
\hline 1.8 & 12 & $5.67 \pm 0.48$ & $8.35 \pm 0.61$ & $14.6 \pm 0.45$ & $9.27 \pm 1.86$ & $14.36 \pm 2.56$ & $17.72 \pm 2.67$ \\
\hline 3.6 & 12 & $13.95 \pm 0.56$ & $24.59 \pm 0.78$ & $41.48 \pm 0.75$ & $11.27 \pm 1.98$ & $23.58 \pm 2.49$ & $40.64 \pm 3.28$ \\
\hline 7.2 & 12 & $16.25 \pm 0.67$ & $57.73 \pm 1.18$ & $67.42 \pm 1.51$ & $23.62 \pm 3.12$ & $54.87 \pm 4.10$ & $68.64 \pm 4.35$ \\
\hline
\end{tabular}




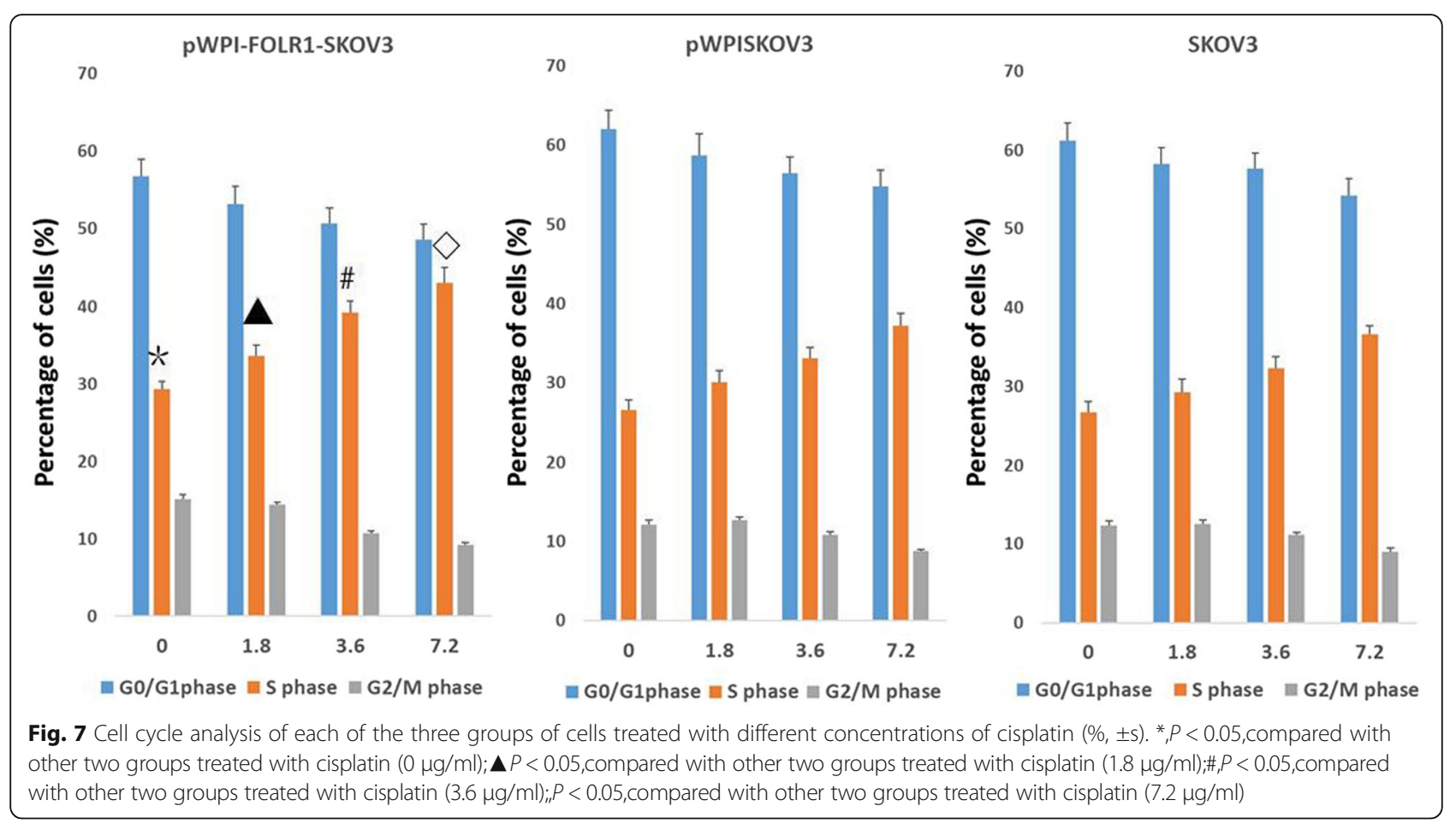

cisplatin. We hypothesize that changes in FOLR1 expression and folate metabolism directly or indirectly contribute to cisplatin-induced apoptosis in ovarian cancer and influence cisplatin sensitivity. A main therapeutic goal is to limit multidrug resistance and improve the clinical efficacy of chemotherapy. This, in turn, would likely improve patient prognosis and survival.

Here, we find that, in the absence of cisplatin treatment, the proportion of cells overexpressing FOLR1 in S phase is significantly increased compared to the two control groups. One group reported that FOLR1 expression in ovarian cancer negatively correlated with the loss of the potential tumor suppressor gene caveolin [19].
Here, we find that treatment of SKOV3 cells with cisplatin resulted in $S$ phase arrest. Those with FOLR1 overexpression showed the most dramatic increase in Sphase fraction following cisplatin treatment, consistent with the fact that this group was most sensitive to the chemotherapy. This is the first description of its kind, as there are no other publications describing a link between this pathway and folate metabolism.

In summary, we find that FOLR1 is highly expressed in ovarian cancer but is reduced following multidrug resistance. FOLR1 may be a useful biomarker for ovarian cancer, and it may be useful as a therapeutic application to improve sensitivity to cisplatin treatment [20].
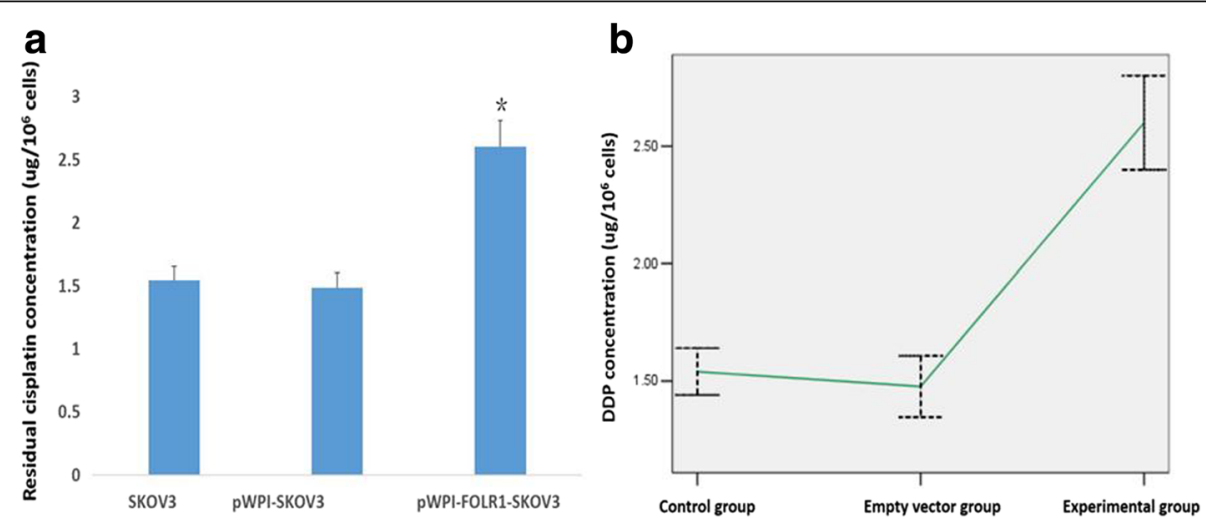

Fig. 8 Residual cisplatin concentration in three groups treated by the same reference concentration after $48 \mathrm{~h}(\mathbf{a})$. ${ }^{*}, P<0.05$, compared with the two control groups. Curve of residual cisplatin concentration in three groups treated by the same reference concentration after $48 \mathrm{~h}$ (b). Control group: SKOV3,Empty vector group: pWPI-SKO3,Experimental group: pWPI-FOLR1-SKOV3 


\section{Conclusions}

In summary, we find that FOLR1 is highly expressed in ovarian cancer but is reduced following multidrug resistance. FOLR1 may be a useful biomarker for ovarian cancer, and it may be useful as a therapeutic application to improve sensitivity to cisplatin treatment [20].

\section{Methods}

\section{Detection of FOLR1 protein in ovarian tissue}

All ovarian tissues were lysed, and protein samples were run by SDS-PAGE. Proteins were then transferred to PVDF membranes. Membranes were blocked for one hour at room temperature in PBS containing 5\% milk/ $0.1 \%$ Tween. Membranes were then washed in PBSTween $(0.1 \%)$ and incubated overnight with FOLR1 goat anti-human polyclonal antibody and goat anti-human GAPDH polyclonal antibody in PBS containing 5\% milk at $4{ }^{\circ} \mathrm{C}$. The next day, membranes were washed with PBS-Tween and incubated for two hours at room temperature with infrared fluorescent dye-labeled donkey anti-goat secondary antibody in PBS containing 5\% milk. Blots were washed with PBS-Tween, and proteins were visualized using chemiluminescence reagents. The infrared fluorescence Odyssey imaging system was used to scan and analyze gray values and to calculate the relative expression of FOLR1.

\section{Effect of cisplatin on SKOV3 cells}

Full-length FOLR1 was PCR-amplified from pOTB7. Primer sequences contained EcoRI and XhoI sites. The amplified product was digested, purified, dephosphorylated, and then ligated into the $\mathrm{pWPI}$ vector to generate the recombinant plasmid pWPI-FOLR1. This recombinant plasmid was then transformed into $E$. coli, isolated, and sequenced. pWPI-FOLR1 was packaged with pCMVdR8.74 and pMD2.G to produce lentivirus, which was used to infect SKOV3 cells. Flow cytometry using green fluorescence was performed to sort pWPI-FOLR1-SKOV3 positive cells. Control cells infected with lentivirus containing empty pWPI vector (pWPI-SKOV3) were generate in a similar manner. Untransfected SKOV3 cells were used as a blank control (SKOV3). Overexpression of FOLR1 was confirmed at the RNA and protein level by RT-PCR and Western blot, respectively.

\section{MTT assay following cisplatin treatment}

Cells were cultured for $24 \mathrm{~h}$ and then treated with increasing concentrations of cisplatin $(0.5,1,2,4,8,16$, 32 , and $64 \mu \mathrm{g} / \mathrm{ml})$; treatment was maintained for $48 \mathrm{~h}$. The growth inhibition rate of each sample was calculated. Half maximal inhibitory concentration $\left(\mathrm{IC}_{50}\right)$ software was used to obtain the $\mathrm{IC}_{50}$ of cisplatin in each of the three groups of cells. Concentration was normalized based on the $\mathrm{IC}_{50}$ of pWPI-FOLR1-SKOV3 cells treated with cisplatin. Concentrations of the three groups were $0.5 \times \mathrm{IC}_{50}, 1 \times \mathrm{IC}_{50}$, and $2 \times \mathrm{IC}_{50}$, and cells were cultured for $24-72 \mathrm{~h}$. Values for each well were calculated, and the inhibition rate of cell growth was determined.

\section{Flow cytometry to measure apoptosis and cell cycle progression following cisplatin treatment}

Cells were cultured with increasing concentrations of cisplatin and incubated for 24, 48, and $72 \mathrm{~h}$. PE-annexin $\mathrm{V}$ and 7 -AAD ( $1 \mu \mathrm{l}$ each) were mixed and added to cells. This was incubated for $15 \mathrm{~min}$ at room temperature in the dark. Next, $400 \mu \mathrm{l}$ of ice-cold binding buffer was added and mixed gently before the cell preparations were examined by flow cytometry. Flow cytometry was then used to analyze the rate of apoptosis. For cell cycle analysis, cells were treated with cisplatin for $48 \mathrm{~h} .1 \mu \mathrm{l}$ RNA enzyme and $10 \mu \mathrm{l}$ Triton X-100 were added to cells at room temperature for $30 \mathrm{~min}$. Next, $1 \mu \mathrm{l}$ PI was added and incubated at $4{ }^{\circ} \mathrm{C}$ for $30 \mathrm{~min}$ in the dark. Finally, flow cytometry was performed.

\section{Statistical analysis}

All experiments were performed at least three times, and statistical analysis was performed using SPSS13.0 software (SPSS Inc., Chicago, USA). The values were expressed as mean \pm SD. ANOVA was used for comparisons made between more than two groups. Significance was set at $P<0.05$. Dunnett's post hoc test was used to analyze multiple comparisons. $P$ values of less than 0.05 $(P<0.05)$ were considered to be statistically significant.

\section{Abbreviations \\ 7-AAD: 7-amino-actinomycin; ANOVA: The analysis of variance; \\ CA125: Cancer antigen 125; CR: Complete response; DDP: Cisplatin; DMEM: Dulbecco's modified eagle's medium; DMSO: Dimethyl sulfoxide; DNA: Deoxyribonucleic acid; EOC: Epithelial ovarian cancer; \\ FIOG: International Federation of Gynaecology and Obstetrics; FOLR1: Folate binding protein; GAPDH: Glyceraldehyde 3-phosphate dehydrogenase; GPI: Glycosyl phosphatidylinositol; HPLC: High-performance liquid chromatography; $\mathrm{IC}_{50}$ : Half maximal inhibitory concentration; MDR: Multi- drug resistance; mRNA: messenger RNA; MTT: 3-(4,5-dimethyl-2-thiazolyl)-2,5- diphenyl-2-H-tetrazolium bromide; PD: Progressive disease; PI: Propidium iodide; PR: Partial response; PVDF: Polyvinylidene fluoride; RNA: Ribonucleic acid; RT-PCR: Reverse transcription polymerase chain reaction; SD: Stable disease; SDS-PAGE: Sodium dodecyl sulphate-polyacrylamide gel electrophoresis}

\section{Acknowledgements}

Not applicable.

Funding

The study was supported by the Guangxi Natural Science Foundation Nanning China. (Grant no. 2014jjAA40637). and the Ministry of Education Special Fund for Ph.D. Programs (Grant no. 20134503110009).

Availability of data and materials

All data generated or analyzed during this study are included in this published article.

\section{Authors' contributions}

This study was conceived and designed by LL. HM-j and ZW finished the specific experiments. W-Q and $Y Z-j$ were in charge of specimens preparation. 
LS finished this manuscript and submitting for publication. All authors read and approved the final manuscript.

\section{Ethics approval and consent to participate}

The study was endorsed by the Ethics Committee of the Guangxi Medical University. All patients received an explanation concerning the aims of the study and provided signed informed consent.

\section{Consent for publication}

Not applicable.

\section{Competing interests}

The authors declare that they have no competing interests.

\section{Publisher's Note}

Springer Nature remains neutral with regard to jurisdictional claims in published maps and institutional affiliations.

\section{Author details}

${ }^{1}$ Department of Gynecology Oncology, Tumor Hospital of Guangxi Medical University, Nanning 530021, China. ${ }^{2}$ Department of Gynecology, Chongqing Three Gorges Central Hospital, Wanzhou District of Chongqing 404000, China.

Received: 28 March 2017 Accepted: 4 February 2018

Published online: 13 February 2018

\section{References}

1. Leitao MM Jr, Chi DS. Surgical management of recurrent ovarian cancer Semin Oncol. 2009;36(2):106-11.

2. Ragoussis J, Senger G, Trowsdale J, Campbell IG. Genomic organization of the human folate receptor genes on chromosome 11q13. Genomics. 1992; 14(2):423-30.

3. Figini M, Ferri R, Mezzanzanica D, Bagnoli M, Luison E, Miotti S, Canevari S. Reversion of transformed phenotype in ovarian cancer cells by intracellular expression of anti folate receptor antibodies. Gene Ther. 2003:10(12):1018-25.

4. Ma DW, Finnell RH, Davidson LA, Callaway ES, Spiegelstein O, Piedrahita JA, Salbaum JM, Kappen C, Weeks BR, James J, et al. Folate transport gene inactivation in mice increases sensitivity to colon carcinogenesis. Cancer Res. 2005:65(3):887-97.

5. Sierra $\mathrm{EE}, \mathrm{Goldman} I \mathrm{D}$. Recent advances in the understanding of the mechanism of membrane transport of folates and antifolates. Semin Oncol. 1999:26(2 Suppl 6):11-23

6. Shen DW, Su A, Liang XJ, Pai-Panandiker A, Gottesman MM. Reduced expression of small GTPases and hypermethylation of the folate binding protein gene in cisplatin-resistant cells. Br J Cancer. 2004;91(2):270-6.

7. Dainty LA, Risinger Jl, Morrison C, Chandramouli GV, Bidus MA, Zahn C, Rose GS, Fowler J, Berchuck A, Maxwell GL. Overexpression of folate binding protein and mesothelin are associated with uterine serous carcinoma. Gynecol Oncol. 2007;105(3):563-70.

8. Markert S, Lassmann S, Gabriel B, Klar M, Werner M, Gitsch G, Kratz F, Hasenburg A. Alpha-folate receptor expression in epithelial ovarian carcinoma and non-neoplastic ovarian tissue. Anticancer Res. 2008; 28(6A):3567-72.

9. Siu MK, Kong DS, Chan HY, Wong ES, Ip PP, Jiang L, Ngan HY, Le XF, Cheung AN. Paradoxical impact of two folate receptors, FRalpha and RFC, in ovarian cancer: effect on cell proliferation, invasion and clinical outcome. PLoS One. 2012;7(11):e47201.

10. Yuan Y, Nymoen DA, Dong HP, Bjorang O, Shih le M, Low PS, Trope CG, Davidson B. Expression of the folate receptor genes FOLR1 and FOLR3 differentiates ovarian carcinoma from breast carcinoma and malignant mesothelioma in serous effusions. Hum Pathol. 2009:40(10):1453-60.

11. Eltabbakh GH, Mount SL, Beatty B, Simmons-Arnold L, Cooper K, Morgan A. Factors associated with cytoreducibility among women with ovarian carcinoma. Gynecol Oncol. 2004;95(2):377-83.

12. Kurosaki A, Hasegawa K, Kato T, Abe K, Hanaoka T, Miyara A, O'Shannessy DJ, Somers EB, Yasuda M, Sekino T, et al. Serum folate receptor alpha as a biomarker for ovarian cancer: implications for diagnosis, prognosis and predicting its local tumor expression. Int J Cancer J Int Cancer. 2016;138(8): 1994-2002.
13. Chen YL, Chang MC, Huang CY, Chiang YC, Lin HW, Chen CA, Hsieh CY, Cheng WF. Serous ovarian carcinoma patients with high alpha-folate receptor had reducing survival and cytotoxic chemo-response. Mol Oncol. 2012:6(3):360-9.

14. Yakirevich E, Sabo E, Naroditsky I, Sova Y, Lavie O, Resnick MB. Multidrug resistance-related phenotype and apoptosis-related protein expression in ovarian serous carcinomas. Gynecol Oncol. 2006;100(1):152-9.

15. Gibb RK, Taylor DD, Wan T, O'Connor DM, Doering DL, Gercel-Taylor C. Apoptosis as a measure of chemosensitivity to cisplatin and taxol therapy in ovarian cancer cell lines. Gynecol Oncol. 1997;65(1):13-22.

16. Jeong JJ, Park N, Kwon YJ, Ye DJ, Moon A, Chun YJ. Role of annexin A5 in cisplatin-induced toxicity in renal cells: molecular mechanism of apoptosis. J Biol Chem. 2014;289(4):2469-81.

17. Feng $X$, Li L, Jiang $H$, Jiang $K$, Jin $Y$, Zheng J. Dihydroartemisinin potentiates the anticancer effect of cisplatin via mTOR inhibition in cisplatin-resistant ovarian cancer cells: involvement of apoptosis and autophagy. Biochem Biophys Res Commun. 2014;444(3):376-81.

18. Lin J, Spidel JL, Maddage CJ, Rybinski KA, Kennedy RP, Krauthauser CL, Park YC, Albone EF, Jacob S, Goserud MT, et al. The antitumor activity of the human FOLR1-specific monoclonal antibody, farletuzumab, in an ovarian cancer mouse model is mediated by antibody-dependent cellular cytotoxicity. Cancer Biol Ther. 2013;14(11):1032-8.

19. Bagnoli M, Canevari S, Figini M, Mezzanzanica D, Raspagliesi F, Tomassetti A, Miotti S. A step further in understanding the biology of the folate receptor in ovarian carcinoma. Gynecol Oncol. 2003;88(1 Pt 2):S140-4.

20. Xia W, Low PS. Folate-targeted therapies for cancer. J Med Chem. 2010; 53(19):6811-24

\section{Submit your next manuscript to BioMed Central and we will help you at every step:}

- We accept pre-submission inquiries

- Our selector tool helps you to find the most relevant journal

- We provide round the clock customer support

- Convenient online submission

- Thorough peer review

- Inclusion in PubMed and all major indexing services

- Maximum visibility for your research

Submit your manuscript at www.biomedcentral.com/submit
Biomed Central 